\title{
GERMINAÇÃO DE SEMENTES DE TRIGO TRATADAS COM ZINCO E BORO
}

\author{
Maicon Marinho Vieira Araujo ${ }^{1}$, Janaína Rosa Sousa ${ }^{1}$, Elisangela Clarete Camili ${ }^{1}$
}

\footnotetext{
${ }^{1}$ Universidade Federal de Mato Grosso, Cuiabá, MT. E-mail: maiconmarinho@outlook.com, janainards@ @otmail.com, ecamili@ufmt.br
}

\section{RESUMO}

Objetivou-se, neste trabalho, avaliar o efeito da aplicação de fontes de zinco e boro sobre a qualidade fisiológica de sementes de trigo. A aplicação de $\mathrm{Zn}$ em associação com B via tratamento de sementes, promoveu efeitos benéficos sobre a qualidade fisiológica de sementes de trigo. A melhor associação entre os elementos Zn e B ocorreu com a mistura de sulfato de zinco e ácido bórico.

Palavras-chave: Ácido bórico, Borato de sódio, Sulfato de zinco, Tratamento de sementes, Triticum aestivum

\section{GERMINATION OF WHEAT SEEDS TREATED WITH ZINC AND BORON}

\begin{abstract}
The aiming of this study was to evaluate the effect of sources of zinc and boron on physiological seed quality of wheat. The application of $\mathrm{Zn}$ in association with B via seed treatment, promoted beneficial effects on the physiological quality of wheat seeds. The best association between $\mathrm{Zn}$ and B elements occurred with zinc sulfate mixture and boric acid.
\end{abstract}

Keywords: Boric acid, Sodium borate, Zinc sulfate, Seed treatment, Triticum aestivum

\section{INTRODUÇÃO}

O Triticum aestivum L., originário do sudoeste asiático, foi introduzido na Índia, China e Europa onde existem relatos datando o cultivo desta espécie desde 5.000 a.C. Os maiores produtores mundiais de trigo são China, Índia e Rússia. O Brasil possui uma área de cultivo de aproximadamente 1,9 milhão de hectares, com produção ao redor de
4,3 milhões de toneladas, perfazendo uma produtividade de $2.300 \mathrm{~kg}$ ha-1 (CONAB, 2014).

Apesar do Brasil ser altamente dependente da importação desse grão, o País tem condições de ser autossuficiente na produção de trigo, porém, fatores como dificuldade de comercialização, melhor qualidade do produto estrangeiro, baixa 
tecnologia e falta de informações por parte dos produtores brasileiros têm se apresentado como obstáculos para o alcance de maiores rendimentos (CAMPONOGARA et al., 2015).

A expansão das áreas agrícolas, o uso de fertilizantes NPK concentrados e o aumento do rendimento das diversas culturas nas safras, resultante de técnicas mais avançadas advindas da pesquisa podem, ao longo dos anos, acarretar o aparecimento de deficiências de micronutrientes no solo e, consequentemente comprometer os índices de produção. A manutenção dos teores adequados de micronutrientes disponíveis para as plantas merece atenção especial no sentido de se garantir e melhorar os bons resultados alcançados (LEANDRO et al., 2002).

$$
\text { O zinco ( } \mathrm{Zn}) \text { e o boro (B) são os }
$$
micronutrientes que, com maior frequência, mostram-se deficientes em solos brasileiros (MALAVOLTA, 2006). Estima-se que cerca de 170 milhões de ha de solos, sob vegetação de Cerrado no Brasil Central, sejam deficientes em zinco e, cerca de 108 milhões de ha, deficientes em boro. A carência destes micronutrientes reflete no crescimento e na produção, pois desempenham importantes funções nas plantas (LOPES, 1984).
O fornecimento de micronutrientes às culturas pode ser feito diretamente no solo (na forma de adubos), na planta (através de adubação foliar) ou pelo tratamento de sementes (MALAVOLTA, 2006). Devido ao fato do $\mathrm{Zn}$ e o $\mathrm{B}$ serem requeridos em pequenas quantidades pelas plantas, dá-se ênfase à sua adição via tratamento de sementes, por apresentar vantagens relacionadas à uniformidade de distribuição e redução de gastos pela minimização da quantidade aplicada quando comparada com a adubação via solo ou foliar, resultando na racionalização do uso de matérias primas não renováveis (PARDUCCI et al., 1989). O tratamento de sementes com micronutrientes tem como objetivo sua disponibilização para a futura planta. Assim, os teores iniciais de micronutrientes das sementes podem ser aumentados, contribuindo no desenvolvimento e tornando-se importante fonte para a nutrição da planta oriunda das sementes enriquecidas (PESSOA et al., 1996).

No entanto, o tratamento de micronutriente via sementes pode causar incorreções, pois há pequena amplitude de variação entre a dose recomendada e o aparecimento de deficiência ou toxicidade. Para tanto, busca-se uma alternativa mais precisa para o tratamento de sementes, na 
indústria, aproveitando a etapa de beneficiamento, onde são adicionados os defensivos agrícolas, para acrescentar micronutrientes (RIBEIRO et al., 1994). Resta conhecer a qualidade fisiológica das sementes tratadas com zinco e boro, e se ocorre incompatibilidade ou não da aplicação simultânea destes dois micronutrientes.

Em virtude disso, objetivou-se avaliar o efeito da aplicação de fontes de zinco e boro sobre a qualidade fisiológica de sementes de trigo.

\section{MATERIAL E MÉTODOS}

O experimento foi instalado e conduzido no Laboratório de Sementes da Universidade Federal de Mato Grosso, localizado no município de Cuiabá, MT. Para a condução do experimento foram utilizadas sementes de trigo de cinco cultivares: BRS 264, IAC 381, Supera, Quartzo e Valente, armazenadas durante oito meses em câmara seca $\left(17{ }^{\circ} \mathrm{C}\right.$ e $55 \%$ U.R.), provenientes da safra 2014.

O delineamento foi o inteiramente casualizado em esquema fatorial 5 × 6 , sendo cinco cultivares de trigo e seis diferentes combinações dos micronutrientes zinco e boro, com quatro repetições. Utilizou-se com fontes de zinco e boro o sulfato de zinco $\left(\mathrm{ZnSO}_{4}\right)$ com $21 \%$ de $\mathrm{Zn}$, borato de sódio ou bórax $\left(\mathrm{Na}_{2} \mathrm{~B}_{4} \mathrm{O}_{7} \cdot 10 \mathrm{H}_{2} \mathrm{O}\right)$ e ácido bórico $\left(\mathrm{H}_{3} \mathrm{BO}_{3}\right)$ com $11,3 \%$ e $17 \%$ de $\mathrm{B}$, respectivamente.

Os tratamentos foram dispostos em: 1. sulfato de zinco $(Z) ; 2$. borato de sódio (B1); 3. ácido bórico (B2); 4. sulfato de zinco + borato de sódio $(\mathrm{Z}+\mathrm{B} 1)$; 5. sulfato de zinco + ácido bórico $(\mathrm{Z}+\mathrm{B} 2)$ e 6. testemunha $(\mathrm{T})$, nas doses 2,50 g de Zn Kg-1 e 0,15g B Kg-1 de sementes.

As sementes foram tratadas utilizando-se $0,3 \mathrm{~kg}$ de sementes de cada cultivar, adicionando-se a mistura dos micronutrientes em sacos plásticos. A agitação das sementes foi realizada até a completa distribuição do produto e cobertura das sementes. Posteriormente, as sementes tratadas foram colocadas para secar em condição ambiente por 1 hora.

Para determinação do teor de água (TA) das sementes utilizaram-se quatro repetições de $5,0 \mathrm{~g}$ de sementes por tratamento, conforme as Regras para Análise de Sementes - RAS (BRASIL, 2009).

$\mathrm{O}$ peso Hectolítritro $(\mathrm{PH})$ foi avaliado através da pesagem de quatro subamostras em balança hectolítrica, com capacidade de um quarto de litro de sementes e os resultados foram expressos em quilogramas por cem litros (kg hL-1), baseado nas Regras para Análise de Sementes (BRASIL, 2009). 
O teste padrão de germinação (TPG) foi realizado em rolo de papel tipo Germitest, na temperatura de $20^{\circ} \mathrm{C}$, com quatro repetições de 50 sementes por tratamento, sendo a primeira contagem realizada quatro dias após a semeadura (DAS) e a última aos oito DAS (BRASIL, 2009).

Os comprimentos médios da parte aérea (CMPA) e raiz (CMR) das plântulas foram obtidos com quatro repetições de 20 sementes por tratamento, sendo medidas as plântulas aos cinco DAS, com auxílio de régua graduada em milímetros (KRZYZANOWSKI et al., 1999).

Avaliou-se a massa da matéria seca da parte aérea (MSPA) e raiz (MSR) das plântulas logo após a mensuração do comprimento, quando estas foram seccionadas, separando-se a parte aérea do sistema radicular, sendo a parte aérea e raízes imediatamente pesadas. Em seguida, o material foi adicionado em saco de papel e mantido em estufa de ventilação forçada sob temperatura de $65^{\circ} \mathrm{C}$ por 24 horas.

Posteriormente, foi avaliada a massa da matéria seca, utilizando-se balança de precisão $(0,0001 \mathrm{~g})$ e os resultados expressos em mg plântula ${ }^{-1}$, conforme recomendações de Vieira e Carvalho (1994).

Realizou-se o envelhecimento acelerado (EA) das sementes em caixas plásticas tipo "gerbox", possuindo em seu interior uma bandeja de tela de aço inoxidável, onde as sementes foram distribuídas de maneira a formarem uma camada simples sobre a superfície da tela. No interior de cada compartimento individual foram adicionados $40 \mathrm{~mL}$ de água. As caixas, tampadas, foram mantidas em câmara incubadora tipo B.O.D. a $43^{\circ} \mathrm{C}$ por um período de 48 horas. Determinou-se o grau de umidade das sementes após o período de envelhecimento, visando à avaliação da uniformidade das condições do teste. Decorrido o período de envelhecimento, instalou-se o teste padrão de germinação conforme anteriormente descrito, computando-se a porcentagem de plântulas normais no quarto dia após a semeadura. Os resultados foram expressos em porcentagem média de plântulas normais observadas para cada amostra, conforme Ohlson et al. (2010).

Os resultados foram submetidos à análise de variância (ANOVA) e as médias comparadas pelo teste de Scott e Knott ao nível de 5\% de probabilidade, com auxílio do programa estatístico Assistat versão 7.6 beta (SILVA, 2011).

\section{RESULTADOS E DISCUSSÃO}

A análise de variância revelou que a germinação não foi influenciada pela 
aplicação de Zn e B, independente da fonte empregada, bem como da mistura utilizada (Tabela 1). Esses resultados indicam que a aplicação de Zn e B não prejudicam a geminação de sementes de trigo e, corroboram os dados de Tavares et al. (2013), que concluíram que o tratamento de sementes de trigo com micronutrientes ( $\mathrm{Zn}, \mathrm{B}$ e Mo) não afeta a germinação. Resultados semelhantes, foram encontrados por Ribeiro et al. (1994), quando avaliaram sementes de milho tratadas com diferentes fontes de $\mathrm{Zn}$ e B.

A aplicação das fontes de $\mathrm{Zn}$ e B influenciaram no vigor das sementes tratadas, tanto quando aplicados de maneira individualizada, quanto em mistura das fontes (Figura 1).

A análise estatística revelou significância para a interação entre os fatores cultivares de trigo e fontes de $\mathrm{Zn}$ e B aplicadas via tratamento de sementes para as variáveis comprimento médio da parte aérea (CMPA) e de raiz (CMR).

O zinco ativa as peptidases, intensificando a hidrólise das proteínas de reserva e, com isso, a suplementação de esqueletos carbônicos ao eixo embrionário, acelerando ou intensificando seu crescimento. Ativa também as enzimas RNA e DNA polimerase e, consequentemente, a síntese de proteínas pelo eixo embrionário, o qual originará a plântula. Além disso, o Zn é necessário para a síntese de auxina, fitormônio que participa do processo de divisão e alongamento celular (MARENCO \& LOPES, 2007 e TAIZ \& ZEIGER, 2009).

Estes processos, sendo intensificados pela ação do Zn, durante a germinação, provavelmente originarão uma plântula mais vigorosa (OHSE, 2012). As médias referentes ao CMPA (Tabela 2), tratadas com as fontes de $\mathrm{Zn}$ e B, isoladas e/ou em mistura, apresentaram diferenças significativas.

Tabela 1. Resumo da análise de variância para a germinação (\%) de sementes de trigo (T. aestivum) tratadas com fontes de zinco e boro. Cuiabá, MT, 2015.

\begin{tabular}{ccccccc}
\hline F.V. & G.L. & BRS-254 & IAC-381 & QUARTZO & SUPERA & VALENTE \\
\hline Trat. & 5 & $0,7102^{\mathrm{ns} *}$ & $0,5321^{\mathrm{ns}}$ & $0,9902^{\mathrm{ns}}$ & $1,7028^{\mathrm{ns}}$ & $1,6475^{\mathrm{ns}}$ \\
Res. & 18 & & & & \\
Total & 23 & & & & \\
\hline C.V. $(\%)$ & & 5,97 & 5,45 & 3,38 & 4,84 & 3,41 \\
\hline
\end{tabular}

*ns não significativo $(\mathrm{p} \geq 0,05)$. 


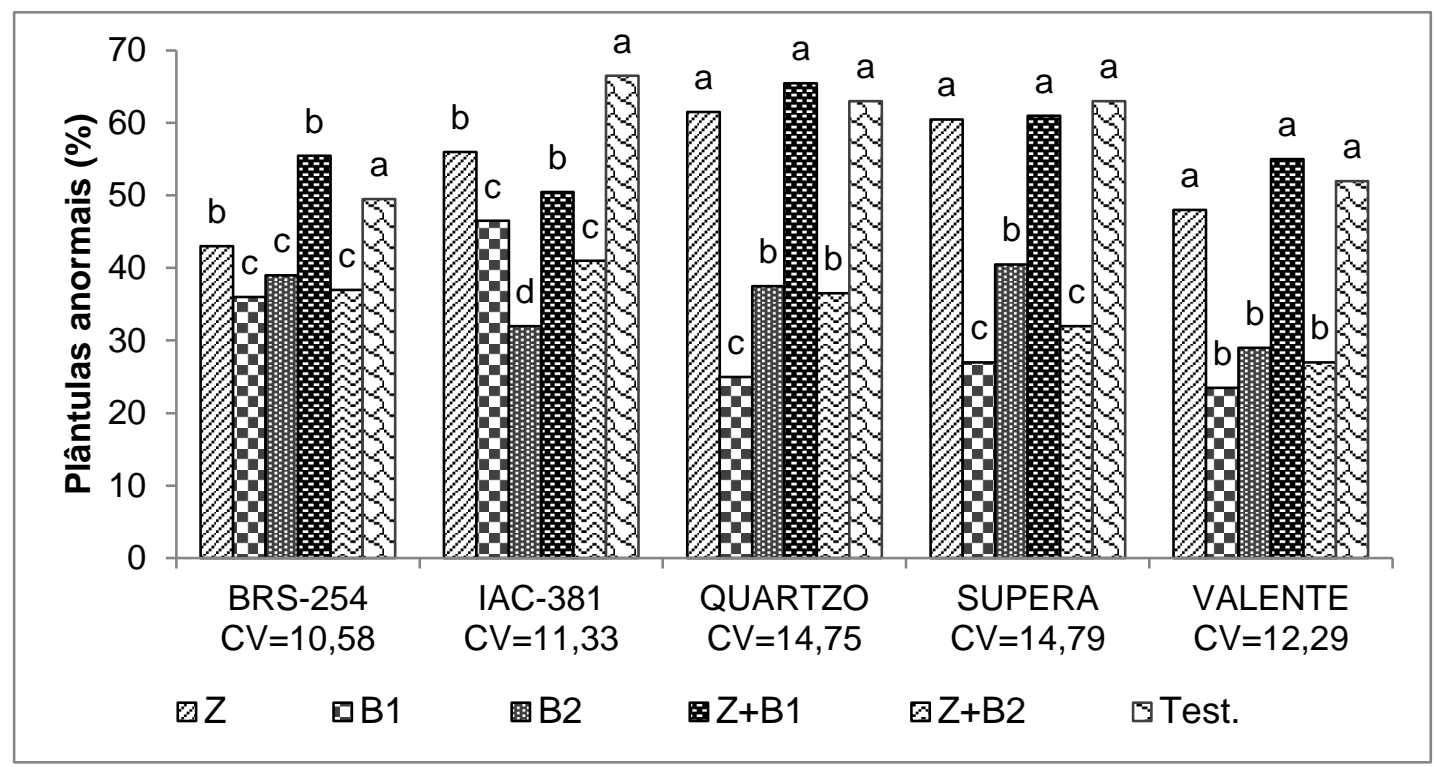

Figura 1. Vigor de sementes de trigo (T. aestivum) tratadas com fontes de zinco e boro. Cuiabá, MT, 2015. $(\mathrm{CV}=\%)$ coeficiente de variação. Médias seguidas pela mesma letra não diferem entre si pelo teste de Scott \& Knott a 5\% de probabilidade.

Tabela 2. Comprimento médio da parte aérea (CMPA) de plântulas de trigo (T. aestivum) tratadas com fontes de zinco e boro. Cuiabá, MT, 2015.

\begin{tabular}{cccccc}
\hline \multirow{2}{*}{ TRATAMENTOS } & \multicolumn{5}{c}{ CMPA $(\mathrm{cm})$} \\
\cline { 2 - 6 } & BRS-254 & IAC-381 & QUARTZO & SUPERA & VALENTE \\
\hline Test. & $8,70 \mathrm{~b}$ & $7,54 \mathrm{c}$ & $8,17 \mathrm{~b}$ & $8,38 \mathrm{c}$ & $10,09 \mathrm{c}$ \\
Z & $7,75^{*} \mathrm{c}$ & $7,63 \mathrm{c}$ & $8,14 \mathrm{~b}$ & $8,08 \mathrm{c}$ & $9,46 \mathrm{c}$ \\
B1 & $9,30 \mathrm{~b}$ & $7,11 \mathrm{c}$ & $9,62 \mathrm{a}$ & $8,71 \mathrm{c}$ & $9,02 \mathrm{c}$ \\
B2 & $9,64 \mathrm{~b}$ & $9,68 \mathrm{~b}$ & $8,73 \mathrm{~b}$ & $10,43 \mathrm{~b}$ & $10,59 \mathrm{~b}$ \\
Z+B1 & $6,94 \mathrm{~d}$ & $7,62 \mathrm{c}$ & $9,29 \mathrm{a}$ & $8,40 \mathrm{c}$ & $15,31 \mathrm{a}$ \\
Z+B2 & $10,48 \mathrm{a}$ & $10,42 \mathrm{a}$ & $10,44 \mathrm{a}$ & $11,7 \mathrm{a}$ & $15,38 \mathrm{a}$ \\
\hline C.V. $(\%)$ & 6,32 & 5,22 & 10,6 & 6,87 & 6,42 \\
\hline
\end{tabular}

* Média de 20 plântulas. Médias seguidas pela mesma letra não diferem entre si pelo teste de Scott \& Knott a 5\% de probabilidade.

O tratamento com sulfato de zinco + ácido bórico $(\mathrm{Z}+\mathrm{B} 2)$ resultou em plântulas com valores de CMPA superiores aos demais, para todas as cultivares estudadas, verificando-se que a mistura elevou em média 54,23\% o CMPA das plântulas em relação à testemunha. No entanto, os tratamentos com sulfato de zinco (Z) e borato de sódio (B1), aplicados isoladamente, apresentaram os menores valores de comprimento médio de plântulas, o que se deve, provavelmente, a algum efeito antagônico provocado por essas fontes de micronutrientes. 
$\mathrm{O}$ efeito benéfico do tratamento de sementes de trigo com $\mathrm{Zn}$ e $\mathrm{B}$, sobre o comprimento de plântulas, pode estar associado ao fato dos elementos ativarem as enzimas desidrogenases, aldolases, enolases e isomerases, intensificando a respiração e, consequentemente, a produção de ATP para os processos que demandam energia, bem como, o fornecimento de precursores para várias rotas biossintéticas (MARECO \& LOPES, 2007). Ainda, o zinco é necessário na síntese do triptofano, aminoácido precursor do AIA (ácido indolilacético - auxina), hormônio promotor do crescimento em plantas (MARSCHNER, 1986; MENGEL \& KIRKBY，1987; FERREIRA \& CRUZ, 1991). Deste modo, a aplicação destes elementos em sementes atua na germinação e no crescimento inicial das plântulas, favorecendo a qualidade física das sementes produzidas, resultando em maior uniformidade, economia e racionalização no uso de reservas não-renováveis

As médias para CMR foram registradas (Tabela 3). Observa-se que houve diferenças entre os tratamentos, nas diferentes cultivares estudadas, exceto para a cultivar IAC-381, onde não se verificou efeito dos tratamentos.

Zinco e boro influenciam no vigor de sementes de trigo, incrementando a massa da matéria seca da parte aérea (MSPA) das sementes (Tabela 4). A análise estatística revelou que o tratamento com sulfato de zinco + ácido bórico (Z+B2) proporcionou o maior incremento na MSPA das plântulas de todas as cultivares. Segundo Funguentto (2010) esse incremento positivo deve-se ao fato do micronutriente zinco ter um importante papel como promotor do crescimento, estando envolvido em diversas rotas metabólicas responsáveis pelo crescimento das plântulas, provocando um acréscimo na área fotossinteticamente ativa, proporcionando um aumento na biomassa seca de plântulas.

Como pode ser observado (Tabela 5) houve efeito significativo dos tratamentos de sementes com fontes de zinco e boro dentro das cultivares, para massa da matéria seca da raiz (MSR) das plântulas de trigo tratadas com micronutrientes, sendo o tratamento $\mathrm{Z}+\mathrm{B} 2$ que proporcionou as maiores médias para massa da matéria seca da raiz. Fageria (2000) afirma que as raízes das plantas são importantes parâmetros de crescimento, devido à sua importância na absorção de nutrientes e água. Deste modo, pode-se observar que o zinco, associado ao ácido bórico, aplicados via tratamento de sementes provocou acréscimo, em média, de 51,1\% na produção de massa de matéria seca se comparado à testemunha. 
Tabela 3. Comprimento médio da raiz (CMR) de plântulas de trigo (T. aestivum) tratadas com fontes de zinco e boro, Cuiabá, MT, 2015.

\begin{tabular}{cccccc}
\hline \multirow{2}{*}{ TRAT } & \multicolumn{5}{c}{ CMR $(\mathrm{cm})$} \\
\cline { 2 - 6 } & BRS-254 & IAC-381 & QUARTZO & SUPERA & VALENTE \\
\hline Test. & $11,20 \mathrm{~b}$ & $12,84 \mathrm{a}$ & $13,35 \mathrm{a}$ & $12,49 \mathrm{~b}$ & $14,24 \mathrm{~b}$ \\
Z & $11,38 \mathrm{~b}$ & $14,13 \mathrm{a}$ & $11,48 \mathrm{~b}$ & $13,80 \mathrm{~b}$ & $14,67 \mathrm{~b}$ \\
B1 & $15,46 \mathrm{a}$ & $13,73 \mathrm{a}$ & $13,61 \mathrm{a}$ & $14,25 \mathrm{~b}$ & $15,56 \mathrm{a}$ \\
B2 & $15,35 \mathrm{a}$ & $12,77 \mathrm{a}$ & $10,78 \mathrm{~b}$ & $15,98 \mathrm{a}$ & $16,42 \mathrm{a}$ \\
Z+B1 & $10,27 \mathrm{~b}$ & $14,13 \mathrm{a}$ & $13,88 \mathrm{a}$ & $15,67 \mathrm{a}$ & $14,10 \mathrm{~b}$ \\
Z+B2 & $14,70 \mathrm{a}$ & $14,47 \mathrm{a}$ & $14,05 \mathrm{a}$ & $15,05 \mathrm{a}$ & $15,33 \mathrm{a}$ \\
\hline C.V. $(\%)$ & 10,05 & 10,02 & 10,18 & 8,94 & 4,82 \\
\hline
\end{tabular}

(TRAT.) Tratamento. (Test.) Testemunha.

Tabela 4. Massa da matéria seca da parte aérea (MSPA) de plântulas de trigo (T. aestivum) tratadas com zinco e boro, Cuiabá, MT, 2015.

\begin{tabular}{cccccc}
\hline \multirow{2}{*}{ TRAT } & \multicolumn{5}{c}{ MSPA $\left(\mathrm{mg} \mathrm{pl}^{-1}\right)$} \\
\cline { 2 - 6 } & BRS-254 & IAC-381 & QUARTZO & SUPERA & VALENTE \\
\hline Test. & $7,26 \mathrm{~b}$ & $6,23 \mathrm{~b}$ & $6,55 \mathrm{~b}$ & $7,51 \mathrm{~b}$ & $6,40 \mathrm{~b}$ \\
Z & $7,90 \mathrm{~b}$ & $7,93 \mathrm{~b}$ & $7,30 \mathrm{~b}$ & $7,67 \mathrm{~b}$ & $7,64 \mathrm{~b}$ \\
B1 & $8,38 \mathrm{~b}$ & $6,76 \mathrm{~b}$ & $7,18 \mathrm{~b}$ & $7,18 \mathrm{~b}$ & $7,14 \mathrm{~b}$ \\
B2 & $8,06 \mathrm{~b}$ & $12,58 \mathrm{a}$ & $14,06 \mathrm{a}$ & $7,33 \mathrm{~b}$ & $8,34 \mathrm{~b}$ \\
Z+B1 & $6,90 \mathrm{~b}$ & $6,51 \mathrm{~b}$ & $6,91 \mathrm{~b}$ & $7,73 \mathrm{~b}$ & $9,81 \mathrm{~b}$ \\
Z+B2 & $9,99 \mathrm{a}$ & $14,34 \mathrm{a}$ & $13,21 \mathrm{a}$ & $12,35 \mathrm{a}$ & $12,93 \mathrm{a}$ \\
\hline C.V. $(\%)$ & 9,17 & 12,11 & 15,95 & 9,28 & 16,89 \\
\hline
\end{tabular}

(TRAT.) Tratamento. (Test.) Testemunha.

Tabela 5. Massa da matéria seca da raiz (MSR) de plântulas de trigo ( $T$. aestivum) tratadas com zinco e boro, Cuiabá, MT, 2015.

\begin{tabular}{cccccc}
\hline \multirow{2}{*}{ TRAT } & \multicolumn{5}{c}{ MSR $\left(\mathrm{mg} \mathrm{pl}^{-1}\right)$} \\
\cline { 2 - 6 } & BRS-254 & IAC-381 & QUARTZO & SUPERA & VALENTE \\
\hline Test. & $5,26 \mathrm{~b}$ & $5,27 \mathrm{c}$ & $5,73 \mathrm{~b}$ & $6,23 \mathrm{~b}$ & $5,45 \mathrm{~b}$ \\
Z & $5,00 \mathrm{~b}$ & $9,67 \mathrm{~b}$ & $4,61 \mathrm{~b}$ & $6,13 \mathrm{~b}$ & $6,43 \mathrm{~b}$ \\
B1 & $5,40 \mathrm{~b}$ & $5,31 \mathrm{c}$ & $4,56 \mathrm{~b}$ & $5,41 \mathrm{~b}$ & $5,42 \mathrm{~b}$ \\
B2 & $9,36 \mathrm{a}$ & $10,92 \mathrm{a}$ & $9,95 \mathrm{a}$ & $7,23 \mathrm{~b}$ & $7,59 \mathrm{~b}$ \\
Z+B1 & $4,50 \mathrm{~b}$ & $6,29 \mathrm{~b}$ & $6,13 \mathrm{~b}$ & $6,07 \mathrm{~b}$ & $6,17 \mathrm{~b}$ \\
Z+B2 & $11,25 \mathrm{a}$ & $11,76 \mathrm{a}$ & $11,43 \mathrm{a}$ & $9,55 \mathrm{a}$ & $10,70 \mathrm{a}$ \\
\hline C.V. $(\%)$ & 25,64 & 9,69 & 21,27 & 16,74 & 18,61 \\
\hline
\end{tabular}

(TRAT.) Tratamento. (Test.) Testemunha. 
Observa-se resposta diferenciada para as fontes de $\mathrm{Zn}$ e B, sendo que o tratamento Z+B2 apresentou as taxas de germinação mais altas para três das cinco cultivares estudadas (BRS-254, Supera e Valente). No caso das cultivares IAC-381 e Quartzo, as maiores médias observadas foram encontradas nos tratamentos com ácido bórico (B2) e borato de sódio (B1) (Tabela 6).

Deste modo, observa-se que os tratamentos com as fontes de $\mathrm{Zn}$ e $\mathrm{B}$ favoreceram a germinação das sementes, podendo ser utilizados para aumentar o vigor de sementes de trigo. Esse fato corrobora com os resultados encontrados por Tavares et al. (2013), quando avaliaram o desempenho fisiológico de sementes de trigo recobertas com micronutrientes. Resultados semelhantes também foram encontrados por Olhson et al. (2010) e Rufino et al. (2013).

Estudos relacionados ao incremento de zinco e boro em sementes e / ou grãos são de grande importância devido a inúmeros benefícios que estes micronutrientes representam, principalmente os incrementos na qualidade das sementes e no crescimento e produção das plantas. Além disso, a deficiência de zinco é responsável por danos na saúde humana, incluindo danos no crescimento físico, sistema imunológico, a capacidade de aprendizagem, e desenvolvimento de câncer (HOTZ \& BROWN, 2004; PRASAD et al., 2007).

Tabela 6. Germinação de sementes de trigo (Triticum aestivum) tratadas com fontes de zinco e boro submetidas ao teste de envelhecimento acelerado, Cuiabá, MT, 2015.

\begin{tabular}{cccccc}
\hline \multirow{2}{*}{ TRAT. } & \multicolumn{5}{c}{ Germinação (\%) } \\
\cline { 2 - 6 } & BRS-254 & IAC-381 & QUARTZO & SUPERA & VALENTE \\
\hline Test. & $50,5 \mathrm{~b}$ & $33,5 \mathrm{~d}$ & $37,0 \mathrm{c}$ & $37,0 \mathrm{c}$ & $48,0 \mathrm{~b}$ \\
Z & $47,0 \mathrm{~b}$ & $44,00 \mathrm{c}$ & $38,5 \mathrm{c}$ & $39,5 \mathrm{c}$ & $52,0 \mathrm{~b}$ \\
B1 & $64,0 \mathrm{a}$ & $53,5 \mathrm{~b}$ & $75,0 \mathrm{a}$ & $73,0 \mathrm{a}$ & $76,5 \mathrm{a}$ \\
B2 & $61,0 \mathrm{a}$ & $68,0 \mathrm{a}$ & $65,5 \mathrm{~b}$ & $55,5 \mathrm{~b}$ & $71,0 \mathrm{a}$ \\
Z+B1 & $44, \mathrm{~b}$ & $49,5 \mathrm{c}$ & $34,5 \mathrm{c}$ & $39,0 \mathrm{c}$ & $45,0 \mathrm{~b}$ \\
Z+B2 & $63,0 \mathrm{a}$ & $59,0 \mathrm{~b}$ & $63,5 \mathrm{~b}$ & $68,0 \mathrm{a}$ & $73,0 \mathrm{a}$ \\
\hline C.V.(\%) & 10,37 & 10,78 & \multicolumn{2}{c}{13,7} & 13,29 \\
\hline
\end{tabular}

(TRAT.) Tratamento. (Test.) Testemunha. 


\section{CONCLUSÕES}

A aplicação de Zn em associação com $\mathrm{B}$, via tratamento de sementes, promove efeitos benéficos sobre a qualidade fisiológica de sementes de trigo.

A melhor associação entre os elementos $\mathrm{Zn}$ e B ocorreu com a mistura de sulfato de zinco e ácido bórico.

\section{REFERÊNCIAS}

BRASIL. Ministério da Agricultura, Pecuária e Abastecimento. 2009. Regras para análise de sementes. Secretaria de Defesa Agropecuária. Brasília: Mapa/ACS, 395p.

CAMPONOGARA, A.; GALLIO, E.; BORBA, W. F.; GEORGIN, J. 2015. O atual contexto da produção de trigo no Rio Grande do Sul. Revista do Centro de Ciências Naturais e Exatas, Santa Maria, v.19, n. 2, p. 246-257.

CONAB, Companhia Nacional de Abastecimento. 2014. Acompanhamento de safra brasileira: grãos, quarto levantamento, janeiro 2014. Companhia Nacional de Abastecimento. Brasília: Conab, $7 \mathrm{p}$.

GONÇALVES JUNIOR, A. C.; PRESTES, A. L.; TRAUTMANN, R. R.; SANTOS, A. L.; ANDREOTTI, M. 2006. Avaliação de extratores e fitodisponibilidade de zinco para a cultura do milho em Latossolo Vermelho eutroférrico. Acta Science Agronomy, Maringá, v.28, n. 1, p.7-12.

KRZYZANOWSKI, F.C.; VIEIRA, R.D.; FRANÇA NETO, J.B. (Ed.). 1999. Vigor de sementes: Conceitos e Testes. Londrina: ABRATES, cap.3, p.1-24.

LEANDRO, W. M.; OLIVEIRA, J. P.; CARVALHO, M. C.; MEDEIROS, J. C.;
FREITAS, L. F.; SOUTO, M. L.; FERREIRA, R. G. 2002. Efeito da gessagem e da adubação com micronutrientes na produção do algodoeiro no cerrado de Goiás. Informações agronômicas. Piracicaba: Potafos, $4 \mathrm{p}$.

LOPES, A. S. 1984 Solos sob cerrado: características, propriedades e manejo. Piracicaba: Potafos. 162p.

MALAVOLTA, E. 2006. Manual de nutrição mineral de plantas. 1 ed. São Paulo: Agronômica Ceres. 638 p.

OHLSON, O. C.; KRZYZANOWSKI, F. C.; CAIEIRO, J. T.; PANOBIANCO, M. 2010. Teste de envelhecimento acelerado em sementes de trigo. Revista Brasileira de Sementes, Londrina, v.32, n.4, p.118124.

PARDUCCI, S.; SANTOS, O. S.; CAMARGO, R. P.; LEÃO, R. M. A.; BATISTA, R. B. 1989. Micronutrientes biocrop. Campinas: Microquímica. $101 \mathrm{p}$. PESSOA, A. C. S.; SANTOS, O. S.; BORTOLUZZI, A. L.; VEDUIN, J. V. R.; PILLON, C. N. 1996. Épocas e formas de aplicação de zinco em milho cultivado em solução nutritiva. Ciência Agrícola, Maceió, v.4, n. 1, p. 43-52.

RIBEIRO, N. D.; SANTOS, O. S. dos; MENEZES, N. L. de. 1994. Efeito do tratamento com fontes de zinco e boro na germinação e vigor de sementes de milho. Scientia Agraria, Piracicaba, v.51, n.3, p.481-485.

RUFINO, C. A.; TAVARES, L. C.; BRUNES, A. P.; FRIEDRICH, F. F.; BARROS, A. C. S. A.; VILLELA, F. A. 2013. Treatment of wheat seed with zinc, fungicide, and polymer: seed quality and yield. Journal of Seed Science, Londrina, v.35, n.1, p.106-112.

SILVA, F. A. S. 2011. ASSISTAT versão 7.6 beta. Campina Grande-PB: Assistência Estatística, Departamento de Engenharia Agrícola do CTRN - 
Universidade Federal de Campina Grande, Campus de Campina.

TAVARES, L. C.; RUFINO, C. A.;

BRUNES, A. P.; FRIEDRICH, F. F.; BARROS, A. C. S. A.; VILLELA, F. A. 2013. Physiological performance of wheat seeds coated with micronutrients. Journal of Seed Science, Londrina, v.35, n.1, p.28-34.

VIEIRA, R. D.; CARVALHO, N. M. 1994. Testes de vigor em sementes. Jaboticabal: FUNEP, p.49-85.

Recebido em: 25/11/2015 Aceito para publicação em: 07/11/2016 